\title{
The Scheme Analysis of Integration of Solar Energy Heater and Architectural in Residential Building
}

\author{
Wang Ruozhu, Zhan Jun and Qian Yongmei*
}

Jilin Jianzhu University, Changchun, Jilin, 130018, P.R. China

\begin{abstract}
In this paper, through introducing the design of real building at the north-east district, the paper mainly studies how to finish the combination on building and solar water heater in the design of residential building, by analyzing the cases about practical project and the climate characteristic, in order to provide references for the utility of solar energy in the resident building design, and promote the extensive apply of solar energy.
\end{abstract}

Keywords: Residential building, solar energy, solar water heater, the integral combination.

\section{SUMMARY}

After two decades of research and development, the use of solar energy in China has made great development, but compared with Europe and the United States and other developed countries, there are still a big gap. Especially the integral combination technology on the solar energy and building, it is basically the initial stage in China. In developed countries, the integral combination technology on photovoltaic and building has already been quite mature, but in China [1], this aspect is still in the stage of pilot and demonstration projects. To achieve the integral combination on solar energy and building, architects have to actively be involved in the design of solar components, though synchronous design, simultaneous construction of building, the use of solar energy system is perfectly integrated into the building, so to finish unified the beautiful and functional building. For a long time, the low-power and high comfort of healthy living environment that has been created by the integral combination on solar energy and building, not only can make families live more naturally and more environmentally friendly, but also can achieve the energysaving and emission- reduction, it will show its more and more irreplaceable position in residential construction, and become the latest highlight in residential construction and be of great significance for achieving the sustainable development of society [2].

The solar water heater is a one-time investment, though expensive than electricity, gas water heater in purchase, but it has no longer investment in the course of use, and it is safe, reliable and easy to operate. By integrative computation, the solar water heater has the least investment [3]. At present, we can see various forms of solar water heater on the roof of the building, it has become the basic consumer goods in people's lives, like a refrigerator, color TV. However, today's solar water heater to which only be considered their own structure and function, it can't be taken

*Address correspondence to this author at the Institute of Civil Engineering, Jilin Jianzhu University, Changchun, 130118,

P.R. China; Tel:13504405206; E-mail: 654675316@qq.com into account the unity with the building, so solar water heaters destroy the overall image of the building almost without exception.

In order to achieve the integral combination on the solar energy systems with building, it is required that in the beginning of the construction planning and design, the use of solar energy systems should be an integral part of the architectural design, such as to reserve the installation location of the construction, to properly resolve the problem of the installation of the collector, to ensure the building's load-bearing function and waterproof, while the pipes of circuit and waterways can be best designed, so the solar system does not affect the building appearances, so that the aesthetics and functionality can be perfectly united. In this paper, through analyzing the real project design at the north district, it is put forward that the suit design plan of the integral combination on solar energy and building, in order to provide references for the utility of solar energy in the resident building design in the future.

\section{THE ANALYSIS OF THE ENGINEERING DESIGN CASE}

For example, in the multi-storey and high-storey residential of a residential area in the north, according to the specific characteristics of the project, it separately is used that the combined programs of rooftop and balcony installations, comparison and analysis of different options, it is proposed that a more reasonable and realizable the combination of design in the north [4].

\subsection{A Case Study of Multi-Storey and Tall Residential Building Applied Centralized Solar Roof Framework}

Generally for the multi-storey and tall residential building, the roofing is flat roof, which is also focusing on parts for architectural modeling. Especially in the upscale residential district, the image of the shape of the external characteristics is attached great importance to developers and designers. In a variety of modeling techniques, the framework is now commonly used method. For flat roofs, 
each unit is usually used a model unit, a variety of frameworks is made outstanding roof with staircase or balcony combined, which breaks sections of the outline as architecture logo. But now most of the framework is purely decorative, does not have specifically use function, as shown in Fig. (1).

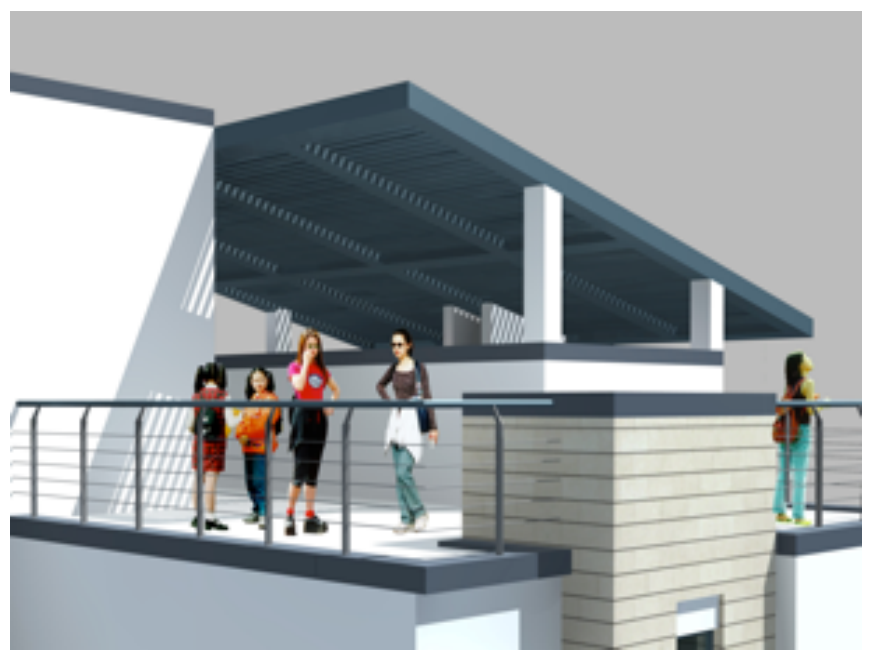

Fig. (1). Roof architecture as a purely decorative member.

Therefore, if architecture and solar water heater are combined, so that it meets the architectural needs and practical functions, and making it more rational, but also to achieve the idea of integration on building and solar water heaters. Design of roof framework in the present case achieves well integral combination on residential building and solar water heater, as shown in Fig. (2).

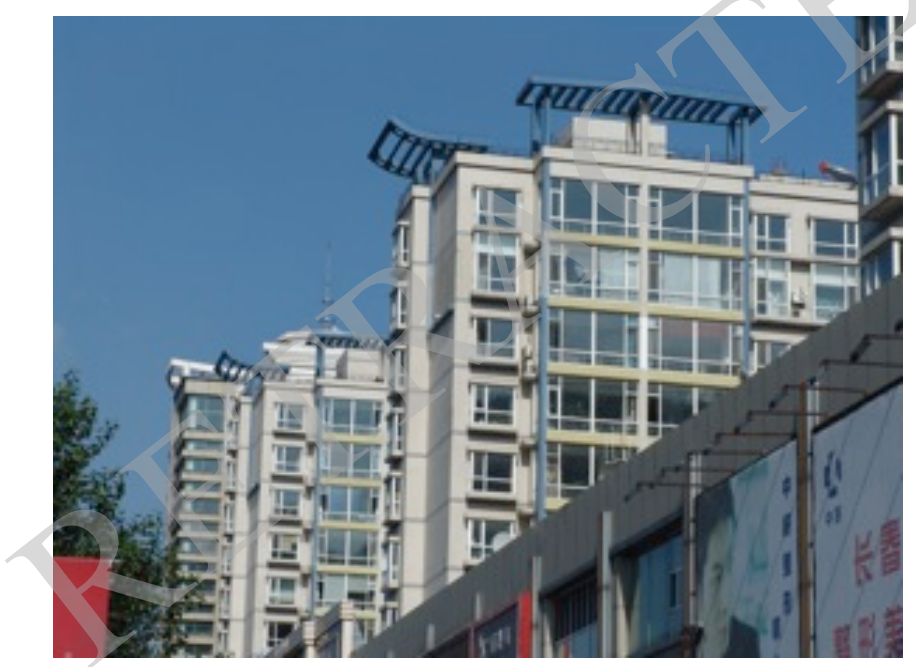

Fig. (2). Effect drawing of roof framework.

\subsubsection{The Practical Procedure in Design}

In the design, the settlement of roof framework solar water heater involves the form of overall water supply systems and solar collectors, the location of solar collector installed and the water tank settled, and the settlement of pipes sets and other related content [1]. Practical approaches are as follows:

1. The form of overall water supply system. The centralized hot water supply system comprised with household hot water supply systems, has the advantages that water quantity can be balanced between users, and collectors can be adequately applied, easy to be combined with construction. Therefore, this system should be preferentially adopted under the same conditions. So there is no need for each household based plumbing and electrical pipes and only need to install centralized collector, water storage tanks and piping. Unified management and maintenance is due to the property sector, the quantity of hot water used is calculated by the manner of sub-metering, which eliminates the user's trouble of purchase, installation, maintenance and management, interior usable space is increased. The ideal situation should be used for district heating, a residential area is a unit concentration solar heating. However, in China it is difficult to achieve recently due to the actual situation. A more realistic approach is the use of a unit of centralized heat-supply, which not only can use effectively and efficiently the solar energy, but also can be also more convenient for management and maintenance, and take full advantage of space and reduce the cost of running. The corresponding area of the supply is determined based on the total area installed collector on the roof.

2. The form of collector. It is adopted that solar collector with the heat pipe made by vacuum tube, which is concentrated into a film (Suitable for the Northeast climate characteristics). The water tank and the collector tube can be separated in this form collector, the solar energy is passed through intermediaries in the tube to the water tank, in which the heat be exchanged with water. This indirectly exchanges, that is forcing double loop split pressurized system, doesn't fear of being frozen, will not create a vacuum tube fouling, fried tubes, capable of running under pressure. Even if there is injuring of a vacuum tube, the system still usually works.

3. The location of collector installed: This is the key to combination with building. The collectors are not placed directly on the roof, but the framework is made by overhead structure raised out of roof on the original structure, which is used as the sites of collector installed (Fig. 2). Framework can be made with reinforced concrete or steel structure, it can be declining or horizontal, thin and intensive collectors can be as the small element inside, which will achieve the perfect combination with building, become architectural features. Intensive tube can also act as a shade element on the roof, thereby the purely decorative components can be multifunctional and diversity of styles can be varied.

4. The position of tank settled: The water tank can be set above the top floor of elevator out of the roof, for unit type residential building, a separate water tank is set in each unit. So that the volume of the tank is small, little impact on the structure, the pipeline of collector and water tank is short, heat lose less, and it is also very convenient that contact the pipelines of water points, it can be done through tube wells in the stairway households. However, the measurement of 
water household should be set in practical application, in order to charge management.

5. The settlement of tube wells. The original staircase pipe is still used well as location of installed pipes entering in the user, so that per household doesn't have to be separate set and the indoor area is corresponding increased.

\subsubsection{The Advantages and Disadvantages of the Design are as Follows}

1. Framework as part of the architectural modeling, full integrating with the architecture, not only is it less easy to form a visual pollution than other unions, instead of styling has a big enhance. In addition, collector framework will become the perfect sunshade component in the summer, whose Fig. (2).

2. The installation of the water heater should be considered in the function of heat insulation is strengthened, thereby indoor temperatures of residential building is reduced in summer, as shown in design stage. Not only to achieve harmonies in functionality and style of elevation, but also to reduce some investments, unnecessary waste and disturbance to other residents.

3. Overhead bracket on the roof is usually at the highest point, with being least blocked, high thermal efficiency, easy to even contiguous layout. Collector is installed on the structure, rather than on the roof, without causing damage to the structures, waterproofing, insulation, and the structural techniques is simple.

4. The bracket installed on the roof does not affect the use of roof space, below which are still activities places of residents and fire exits.

5. The disadvantages of the bracket on the roof is central heating systems applied, late fees may be brought in the use of it, in addition, due to the limited space on the roof, area of heating service is limited, for flat roofs of lower tall building are more appropriate, and for pitched roof best the manner adapted is collector combined with roof.

2.2. The Example of Bracket Adopted on Balcony in Multi-Layer and Lower Tall Residential Building

In design of residential building, the balcony is not only an important functional area and is extremely important factor to affect the elevation style. To be taken into account from elevation effects of a multi-story building, it is difficult to use the bracket installed on the roof. The roof area of tall building is limited, and it will be affected for use effect of the user at the lower storey due to the pipeline is too long. Therefore, the location of balcony facing south becomes another important position of solar collectors installed. At the same time, due to the impacts of urban pollution, energy saving in winter, the specific application, area calculated and other factors, the residential balcony in the northeast region basically is closed. However, the relationship with outdoor has gradually changed from the original high solid bar to low hurdles and even French Windows with protection approaches. And the width occupied by balcony is generally larger, which provides the possibility of bracket set on the balcony as shown in Fig. (3).

\subsubsection{Particular Practices are as Follows}

1. The form of system and location of tank: This form of system uses household collector, forced-circulation type, backwater lines. Layout of water tank of water heater is placed indoors or in combination with balcony, which can reduce the length of pipe, at the same time, avoid the overall effect of elevation to be damaged.

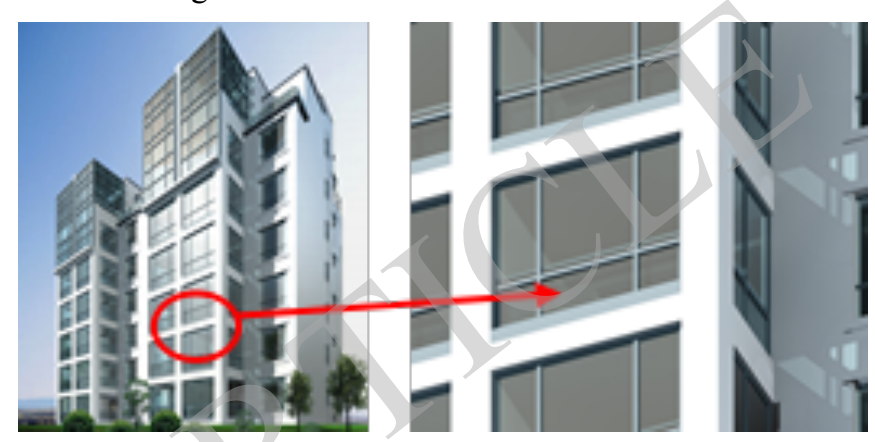

Fig. (3). The program about renderings and the framework of in balcony of multi-storey building.

2. The form and position of the collector: Vacuum tube is generally dark-blue glass tubes, which uses selective absorbing coating and owning distinctive color and texture, the surface is very bright, has a metal texture, so it is appropriate to be used as a decorative framework. Collector tube located outside on the balcony constitutes a form of shading sunshine, this form is not limited by the height of balcony bar, less impacts the internal lighting of balcony, according to the modeling needs it can be designed at one side of the balcony or the middle part of two balcony, and can also be hung on the balcony bar, so that in the vertical direction of the entire building the rows framework with metal texture is formed, which can play a very good decorative effect. In the paper the case is adopted by three different treatments for elevation surface, the effect is very well. As shown in Figs. (4-6).

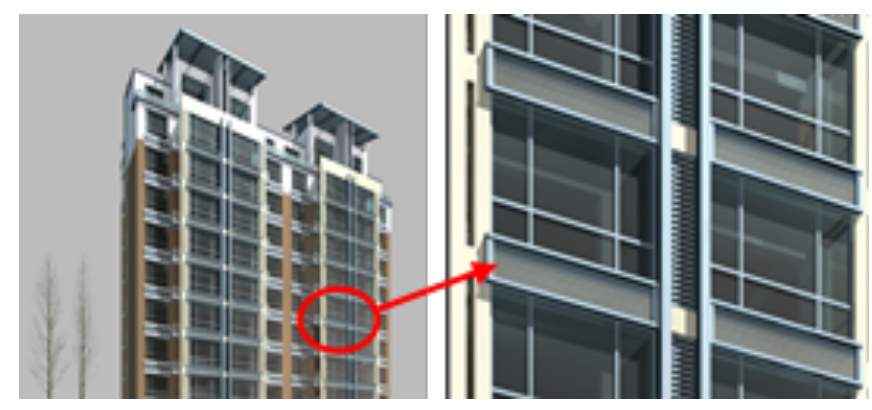

Fig. (4). The first program 1st about renderings and the framework harmed in balcony of tall building.

3. Pipeline laid indoor: Due to water supply pipes of water heaters is running water, which can be used PP$\mathrm{R}$ pipe as a transport pipe in cold water. Return pipe from the water heater to the room, it can be used that the plastic composite pipe (PPR-AL-PPR), steady 
pipe (AL-PPR) or PB pipe (polybutylene pipe). The above pipeline concealed along the wall and the ground will be connected with water point indoor.

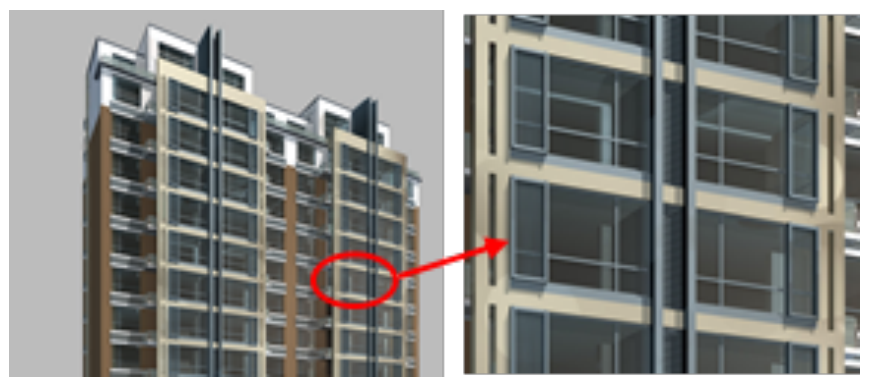

Fig. (5). Program 2nd about renderings and the framework harmed in balcony of tall building.

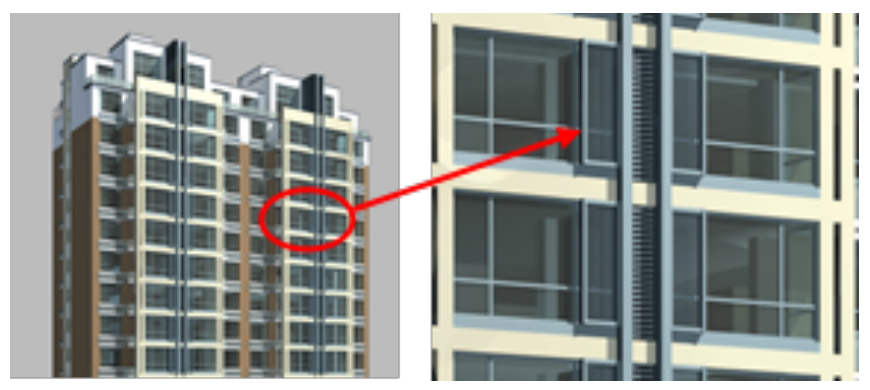

Fig. (6). Program 3rd about renderings and the framework harmed in balcony of tall building.

\subsubsection{Advantages and Disadvantages of this Design are as Follows}

1. Framework is as part of the building, completely merged with building, not only unlike other combination as easy to form pollution of visual form, but is the modeling greatly improved.

2. The installation of water heater is taken into account in design stage. Not only to achieve its harmonies to functionality and architectural style, but also to reduce some investments, and reduce unnecessary waste and disturbance to other residents.

3. The connection distance of collector and tank is closer, heat loss is less. They are very convenient to installation, maintenance, construction, and maintenance, and with high security.

4. It is responsible for the user themselves for the application, management, maintenance of the framework in balcony, and it has no interruption with the other users.

5. The framework in balcony has a certain impact on for users with smaller balcony, when building distance is not enough, users in low-storey is affected largely due to sunlight.

\section{CONCLUSION}

By analyzing the design scheme above, it is known that by careful planning in early process of the design, while taking into account the factors about engineering characteristics, climatic conditions and field conditions and so on, the integration of solar water heaters and building can be achieved very well, so as to achieve solar energy is fully used, at the same time, without building's appearance damaged, even a decorative role is played.

Due to the climate conditions in the north area, current it is suitable for roof bracket and balcony framework. Two ways have their own advantages and disadvantages, if fully taken into account in design, while their advantages can be better played. On the whole, balcony framework can be applied in multi-storey building, lower tall building and tall buildings, roof bracket is more suitable for lower tall building with flat roofs, there are also mosaic solar water heaters in roof applied in multi-storey building, lower tall building with slope roof [4]. So to speak, this is the best way about the integral combination of solar water heater and building. It will become the future direction of development of the solar water heater applications.

The integral combination of solar water heater and building belongs to major innovations in solar energy technology, which has given rise to high priority by government sectors and technologies, industry sectors, and will make solar energy technology of 21 st century up to a new level, and allow the architecture of 21 st century become green ecological solar architecture.

\section{CONFLICT OF INTEREST}

The author confirms that this article content has no conflict of interest.

\section{ACKNOWLEDGMENTS}

This work is financially supported by National Natural Science Foundation of China (51478205).

\section{REFERENCES}

[1] J.J. Zhang, "Study on the Integral combination of High-rise Residential Building and Solar Water Heater", Building Science, pp. 103-105, 2007

[2] R.Z. Wang, "Research on green energy-saving design of residential buildings in Changchun", Master's thesis, 2008

[3] J. J. Zhang, "The combinative research on high-rise residence and the integral combination of the solar water heater", Building Science, pp. 101-102, 2007

[4] S. M. Ao, "The technical progress of the integral combination the solar water heater and building", Academic Journal of Nanjing Industrial University, pp. 102-103, 2005

This is an open access article licensed under the terms of the Creative Commons Attribution Non-Commercial License (http://creativecommons.org/licenses/ by-nc/3.0/) which permits unrestricted, non-commercial use, distribution and reproduction in any medium, provided the work is properly cited. 